\title{
EFEITO DO ÁCIDO NAFTALENO ACÉTICO (ANA) E BENZILAMINOPURINA (BAP) NO AUMENTO DO ÂNGULO DE INSERÇÃO DOS RAMOS EM MACIEIRA ${ }^{1}$
}

\author{
AIKE ANNELIESE KRETZSCHMAR ${ }^{2}$, ANDRÉIA HANSEN OSTER ${ }^{3}$, CARLOS ROBERTO MARTINS ${ }^{4}$, \\ GILMAR ANTONIO NAVA ${ }^{5}$
}

\begin{abstract}
RESUMO - Objetivou-se avaliar a influência dos fitorreguladores ANA (ácido naftaleno acético) e BAP (benzilaminopurina), no aumento do ângulo de inserção de ramos jovens em macieira. O experimento foi conduzido em um pomar comercial da região de Lages-SC, utilizando-se das cultivares Imperial Gala e Fuji, sobre porta-enxerto Marubakaido, testando diferentes doses de fitorreguladores e o arqueamento convencional. Os fitorreguladores foram aplicados com auxílio de algodão, na inserção entre os ramos e o caule, na parte superior dos ramos em crescimento. Os resultados evidenciaram que ANA teve um efeito positivo no arqueamento de ramos, nas doses de 200 a 500 ppm, mas a prática convencional para aumentar o ângulo de inserção dos ramos, através do uso de palitos, continua sendo o melhor método de arqueamento.
\end{abstract}

Termos para indexação: auxinas, citocininas, maçã, arqueamento

\section{THE EFFECT OF NAFTALEN ACETIC ACID (NAA) AND BENZILAMINOPURIN (BAP) IN THE INCREASE OF THE ANGLE OF INSERTION OF THE BRANCHES IN APPLE TREES}

\begin{abstract}
The objective of this experiment was to evaluate the influence of the growth regulators NAA (naftalen acetic acid) and BAP (benzilaminopurin), in the increase of the angle of insertion of the branches in apple trees. The experiment was driven in a commercial orchard area of Lages/SC, where has been cultivated Imperial Gala and Fuji cultivars on rootstock Marubakaido, testing different doses of the regulators compared with the conventional bending. The regulators were applied with cotton aid, in the superior part of the branches in growth, in the insertion between the branch and the stem. The results evidenced that, even NAA tends to have a good effect in the bending of branches, in the doses of 200 to 500 ppm, the conventional practice to increase the angle of insertion of the branches, through the use of toothpicks, continues being the best bending method. Index Terms: auxins, cytokinins, apple, bending
\end{abstract}

Muitas inovações ocorreram ao longo dos anos na forma de condução das macieiras, sendo que os sistemas de condução líder central e líder central modificado são os mais utilizados nos dias de hoje, com densidades variando de 556 a 3.333 plantas/ha (Pereira \& Petri, 2002). Na Europa e EUA, são também utilizados sistemas de altíssima densidade de plantio para macieira, pessegueiro e pereira, com 6.000 a 12.000 plantas/ ha, resultando em produtividades elevadas (Fideghelli, 1991).

$\mathrm{O}$ arqueamento de ramos é fundamental durante o período de formação da macieira, a fim de obter uma boa estruturação dos ramos de produção. A abertura dos ramos laterais favorece maior insolação no interior da copa, melhora a penetração de produtos para controle fitossanitário, proporciona maior facilidade para práticas de raleio e colheita, além de melhorar a qualidade dos frutos (Ebert \& Denardi, 1986).

A prática do arqueamento, preconizada por diversos autores (Tiscornia, 1984; Ebert et al., 1987), é realizada manualmente através da utilização de palitos de madeira durante o período inicial de crescimento dos ramos, o que demanda enorme dispêndio de mão-de-obra.

$\mathrm{O}$ arqueamento dos ramos também pode ser realizado através da utilização de fitorreguladores, tais como auxinas e citocininas.

De acordo com Westwood (1982), o aumento da concentração de auxinas no lado superior da bifurcação do ramo estimula um maior crescimento celular dorsal do ramo e origina um ângulo de inserção mais amplo.

O tratamento de brotos despontados, com ácido indolbutírico (AIB) nas concentrações de 250 a 1.000 ppm, provocou a formação de ângulos de inserção mais amplos em todos os ramos abaixo. Quando se eliminou o fluxo basípeto de auxina pela incisão anelar, obtiveram-se ângulos de inserção mais fechados (Westwood, 1982).

Willians \& Stahly (1968), citados por Faust (1989), observaram que ramificações com ângulo aberto podem ser obtidas através da aplicação de reguladores de crescimento do tipo citocinina, tais como benziladenina (BA) nas gemas.
Este trabalho teve como objetivo verificar a influência de dois fitorreguladores, auxina e citocinina, em diferentes concentrações de ácido naftaleno acético (ANA) e benzilaminopurina (BAP) no aumento do ângulo de inserção de ramos jovens em macieira.

O experimento foi conduzido em um pomar comercial na região de Lages, durante o período de agosto/95 a janeiro/97, nas cultivares Imperial Gala e Fuji, com um ano de idade, sobre porta-enxerto Marubakaido. O delineamento experimental utilizado foi de blocos ao acaso, com 13 tratamentos e 4 repetições. No ano de 1995, os tratamentos constaram de ANA 100; 200; 300; 400 e 500 mg.L.-1 , BAP 100; 200; 300; 400 e $500 \mathrm{mg} . \mathrm{L}^{-1}$, arqueamento com palitos e testemunha constando de algodão embebido em água destilada. Neste ano, as plantas haviam sido recém-plantadas, sendo arqueados os ramos abaixo do líder, com o intuito de formar o primeiro andar da planta.

No ano de 1996, foram testados 11 tratamentos: ANA 200; 300; 400; 500; 600 e 700 mg.L-1 , BAP 500; 600 e 700 mg.L $L^{-1}$, arqueamento com palitos e testemunha, constando de água destilada. Neste ano, as plantas estavam com um ano de idade, sendo arqueados os ramos abaixo do líder, com o intuito de formar o segundo andar da planta. Em 1997, foram testadas apenas as doses de ANA 200; 300; 400 e 500 mg.L. $\mathrm{L}^{-1}$, arqueamento com palitos e testemunha, constando de água destilada, visando a formar o terceiro andar da planta .

Foram escolhidos 5 ramos por planta com 5 a $10 \mathrm{~cm}$ de comprimento. Após a diluição, as diferentes doses dos fitorreguladores foram aplicadas com auxílio de algodão embebido na solução, na inserção entre o ramo e o caule, sendo que o algodão embebido com o fitorregulador ficou em contato apenas com a superfície superior do ramo lateral.

As avaliações foram realizadas após 09; 15; 30 e 43 dias da aplicação dos fitorreguladores na cultivar Imperial Gala e após 15 e 28 dias na cultivar Fuji. O ângulo de inserção foi medido com auxílio de um transferidor, aferindo-se o ângulo a $6 \mathrm{~cm}$ acima da base do ramo, como mostra a Figura 3.

\footnotetext{
${ }^{1}$ (Trabalho 160/2003). Recebido: 22/10/2003. Aceito para publicação: 24/06/2004.

${ }^{2}$ Eng. Agr. Dra., Prof. De Fruticultura, Depto de Fitotecnia, Universidade do Estado de Santa Catarina/UDESC, C.P. 281, CEP 88.502-970, Lages-SC. E-mail: a2aak@cav.udesc.br.

${ }^{3}$ Eng. Agr. M. Sc., Prof. UNIPLAC; E-mail: Hansen@ uniplac.net.

${ }^{4}$ Doutorando em Agronomia - UFPel; E-mail: marticar@ufpel.tche.br.

${ }^{5}$ Doutorando em Agronomia - UFRGS; E-mail: gilmarnava@bol.com.br
} 
TABELA 1 - Efeito do ANAe BAP no aumento do ângulo de inserção de ramos em macieira, cultivar Imperial Gala, em três anos. Lages-SC.

\begin{tabular}{|c|c|c|c|c|c|c|}
\hline \multicolumn{7}{|c|}{ Ângulo de arqueamento observado (média de 4 leituras) } \\
\hline Tratamentos & 199 & & 1996 & & 1997 & \\
\hline Palitos & 81.91 & $\mathrm{a}$ & 82.33 & $\mathrm{a}$ & 72.31 & $\mathrm{a}$ \\
\hline ANA $500 \mathrm{mg} \cdot \mathrm{L}^{-1}$ & 62.71 & $\mathrm{~b}$ & 63.75 & b & 44.50 & $\mathrm{~b}$ \\
\hline ANA $300 \mathrm{mg} \cdot \mathrm{L}^{-1}$ & 62.70 & $\mathrm{~b}$ & 62.58 & $\mathrm{~b}$ & 44.31 & $\mathrm{~b}$ \\
\hline ANA $400 \mathrm{mg} . \mathrm{L}^{-1}$ & 61.78 & $\mathrm{~b}$ & 64.41 & $\mathrm{~b}$ & 45.00 & $\mathrm{~b}$ \\
\hline ANA $200 \mathrm{mg} \cdot \mathrm{L}^{-1}$ & 61.23 & b & 65.16 & $\mathrm{~b}$ & 45.00 & $\mathrm{~b}$ \\
\hline ANA $100 \mathrm{mg} \cdot \mathrm{L}^{-1}$ & 55.58 & c & - & & ------ & \\
\hline BAP $400 \mathrm{mg} . \mathrm{L}^{-1}$ & 54.61 & $\mathrm{~cd}$ & ------- & & ------ & \\
\hline BAP $500 \mathrm{mg} . \mathrm{L}^{-1}$ & 54.48 & $\mathrm{~cd}$ & ------- & & ------ & \\
\hline BAP $100 \mathrm{mg} \cdot \mathrm{L}^{-1}$ & 52.11 & $\mathrm{~cd}$ & ------- & & ------ & \\
\hline BAP $300 \mathrm{mg} \cdot \mathrm{L}^{-1}$ & 51.45 & d & ------- & & ------ & \\
\hline BAP $200 \mathrm{mg} \cdot \mathrm{L}^{-1}$ & 47.41 & e & ------- & & ----- & \\
\hline Testemunha & 46.96 & e & 61.83 & $\mathrm{~b}$ & 45.18 & b \\
\hline ANA $600 \mathrm{mg} \cdot \mathrm{L}^{-1}$ & ------- & & 62.08 & $\mathrm{~b}$ & ------ & \\
\hline ANA $700 \mathrm{mg} \cdot \mathrm{L}^{-1}$ & ------- & & 63.00 & $\mathrm{~b}$ & ----- & \\
\hline BAP $600 \mathrm{mg} \cdot \mathrm{L}^{-1}$ & ------- & & 61.58 & $\mathrm{~b}$ & ------ & \\
\hline BAP $700 \mathrm{mg} \cdot \mathrm{L}^{-1}$ & ------- & & 60.83 & $\mathrm{~b}$ & ------ & \\
\hline
\end{tabular}

* Médias seguidas da mesma letra na coluna não diferem estatisticamente entre si, pelo teste de Tukey, a $5 \%$.

** A testemunha constou de água destilada.

TABELA 2 - Efeito do ANA e BAP no aumento do ângulo de inserção dos ramos em macieira, cultivar Fuji, em dois anos. LagesSC.

\begin{tabular}{|c|c|c|c|c|}
\hline \multicolumn{5}{|c|}{ Ângulo de arqueamento observado (média de 2 leituras) } \\
\hline Tratamentos & 1996 & & 1997 & \\
\hline Palitos & 83.75 & $\mathrm{a}$ & 73.81 & $\mathrm{a}$ \\
\hline ANA $400 \mathrm{mg} \cdot \mathrm{L}^{-1}$ & 72.25 & $\mathrm{~b}$ & 44.93 & bc \\
\hline ANA $200 \mathrm{mg} \cdot \mathrm{L}^{-1}$ & 72.00 & b & 49.87 & b \\
\hline ANA $500 \mathrm{mg} . \mathrm{L}^{-1}$ & 69.62 & $\mathrm{~b}$ & 44.87 & bc \\
\hline BAP 500 mg.L $\mathrm{L}^{-1}$ & 68.87 & bc & ---- & \\
\hline ANA $300 \mathrm{mg} \cdot \mathrm{L}^{-1}$ & 68.75 & bc & 49.18 & $\mathrm{~b}$ \\
\hline ANA $700 \mathrm{mg} \cdot \mathrm{L}^{-1}$ & 68.62 & bc & -------- & \\
\hline BAP 700 mg. $\mathrm{L}^{-1}$ & 67.75 & bc & ------- & \\
\hline Testemunha & 66.25 & bc & 61.83 & $\mathrm{c}$ \\
\hline BAP 600 mg.L $\mathrm{L}^{-1}$ & 64.87 & bc & ------ & \\
\hline ANA $600 \mathrm{mg} . \mathrm{L}^{-1}$ & 63.75 & $\mathrm{c}$ & ------- r - - & \\
\hline
\end{tabular}

* Médias seguidas da mesma letra na coluna não diferem estatisticamente entre

si, pelo teste de Tukey, a $5 \%$.

** A testemunha constou de água destilada.

A análise estatística dos dados foi realizada pelo sistema de análise estatística - SANEST, e as médias foram comparadas pelo teste de Tukey, a 5\% de significância.

Os dados apresentados nas Tabelas 1 e 2 demonstram que o maior ângulo de inserção dos ramos de macieira foi obtido pela prática convencional através do uso de palitos em ambas as cultivares testadas.

No ano de 1995 (Tabela 1), os tratamentos com ANA, nas dosagens de 200 a $500 \mathrm{mg} . \mathrm{L}^{-1}$, provocaram um bom arqueamento de ramos na cultivar Imperial Gala, não diferindo estatisticamente entre si. Estes resultados confirmam as observações de Westwood (1982) de que, quando a concentração de auxina no lado superior dos ramos aumenta, ocorre um estímulo maior de crescimento celular dorsal do ramo, originando um ângulo de inserção mais amplo. Quando comparados com a testemunha, estes tratamentos apresentaram diferença significativa. Já com o BAP, houve apenas um pequeno incremento no ângulo de inserção dos ramos.

Em 1996, nos tratamentos realizados com ANA e BAP(Tabelas 1 e 2), o arqueamento alcançado não diferiu estatisticamente da testemunha, tanto na Imperial Gala quanto na Fuji.

As doses de 200 a $700 \mathrm{mg} . \mathrm{L}^{-1}$ de ANA e $700 \mathrm{mg} . \mathrm{L}^{-1}$ de BAP tiveram efeito fitotóxico (epinastia e enrolamento de folhas) sobre os ramos em ambas as cultivares, o qual teve um aumento diretamente proporcional à dosagem utilizada. Isto pode ter ocorrido devido ao tempo de exposição dos ramos aos fitorreguladores que, neste ano, foi maior devido às condições climáticas ocorridas no dia da aplicação terem sido favoráveis à absorção dos mesmos.

No ano de 1997, não houve diferença significativa entre os tratamentos para a cultivar Imperial Gala, mas houve uma pequena diferença para a cultivar Fuji, observando-se que as doses de ANA 200 e $300 \mathrm{mg} . \mathrm{L}^{-1}$ tiveram um arqueamento superior à testemunha (Tabelas $1 \mathrm{e}$ 2). No entanto, apenas através do uso de palitos foi obtido um ângulo de inserção próximo de $90^{\circ}$.

Observou-se que a prática convencional de arqueamento dos ramos em macieira, com uso de palitos, foi o melhor método para promover a abertura dos ramos. No ano de 1995, o arqueamento de ramos foi influenciado positivamente na dose de $200 \mathrm{mg} . \mathrm{L}^{-1}$ de ácido naftaleno acético (ANA), em relação à testemunha.

\section{REFERÊNCIASBIBLIOGRÁFICAS}

EBERT, A.; KREUZ, C.L.; RAASCH,Z.S.;ZAFFARI,G.R.;BENDER,R.J. Capacidade de produção em macieiras. Florianópolis: EMPASC, 1987, Boletim Técnico, 41 .

EBERT, A.; DENARDI, F. Reguladores de crescimento. In: EMPASC Empresa Catarinense de Pesquisa Agropecuária. Manual da cultura da macieira. Florianópolis: EMPASC, 1986.p. 474 - 492.

PEREIRA, A. J.; PETRI, J.L. Poda e condução da macieira. In: EPAGRI. Manual da cultura da macieira. Florianópolis: EPAGRI, 2002. p.391 $-41$.

FAUST, M. Physiology of temperate zone fruit trees. Beltsville:Ed John Willey Sons, 1989.338p.

FIDEGHELI,C. Manual do podador. Lisboa: Ed. Presença, 1991, 207p.

TISCORNIA J.R. Condução e Poda da Macieira em Pomares Comerciais. Pelotas: EMBRAPA, CNPFT, 1984. (Circular Técnica, 9)

WESTWOOD, M. N. Fruticultura de zonas templadas. Madri: Mundi Prensa, 1982.438p. 